\title{
An air-cooled YASA motor for in-wheel electric vehicle applications
}

\author{
Dave Winterborne, Nick Stannard, Lars Sjöberg, Glynn Atkinson
}

\begin{abstract}
In-wheel motors present a range of opportunities for innovation in electric vehicle design as the torque produced at each of two or four wheels can be controlled individually. A high aspect ratio (large radius, short axial length) motor is required to fit within the wheel. Due to its location, liquid cooling of the inwheel motor is difficult and undesirable, but a high power density is required to reduce the mass-which is particularly important as it is unsprung-and fit the space envelope. Furthermore, a high torque density is required to eliminate the need for a gearbox. These constraints create a real challenge for the design of a machine for this application. An axial field machine using a Yokeless and Segmented Armature (YASA) topology is designed to fit these requirements as such a machine has clear advantages when considering the high aspect ratio. A soft magnetic composite (SMC) material is utilised to carry the flux in its non-planar path without incurring excessive losses or requiring a lamination design which is difficult and expensive to manufacture. A novel cooling arrangement involving heat-spreading elements on each armature segment is employed to improve heat dissipation and hence power density. The design, analysis, manufacturing, and testing of the motor is described in this paper to verify the concept against the requirements outlined above.
\end{abstract}

Index Terms-Electrical Machines, Permanent Magnet machines, Motor Drives and Electrical Machines

\section{INTRODUCTION}

$\mathbf{I}$ N-WHEEL motors enable a number of innovations in electric vehicle (EV) design and control, with applications ranging from electric wheelchairs [1] and scooters [2] through to large EVs [3]. Aside from the elimination of transmissions, driveshafts, and other mechanical parts-simplifying design, and saving cost and weight-additional vehicle controls can be directly implemented. These include anti-lock braking, traction control, and electronic stability control [4].

The space constraint imposed by the wheel rim, which must also accommodate mechanical parts such as brake and suspension components, is the main challenge for in-wheel motor design. High efficiency and low cogging torque are also key [5].

Numerous comparative studies have shown that when the space available is larger in the radial direction than in the axial direction (a high aspect ratio) axial flux topologies offer higher performance than traditional radial flux machines, largely due

Dave Winterborne and Glynn Atkinson are with Newcastle University, UK (email: dave.winterborne@ncl.ac.uk,glynn.atkinson@ncl.ac.uk).

Nick Stannard was with Newcastle University, UK (email: nickstannard@gmail.com).

Lars Sjöberg is with Höganäs AB, Sweden (email: Lars.Sjoberg@hoganas.com).

This work has been made possible by the support of Höganäs AB, Sweden, and JSOL Corporation, Japan (developers of JMAG software). to the increasing advantage at higher pole numbers, and a lower proportion of end winding [6].

The Yokeless and Segmented Armature (YASA) motor topology is characterised by a stator composed of magnetically separate poles, each with a single concentrated winding, between two identical rotor plates offset by 180 electrical degrees, such that magnets with the same polarity face each other across the stator [7]. This reduces the amount of soft magnetic material required, hence reducing loss, weight, volume, and cost, and allows a space-efficient coil with short end windings to be used. Previous work has shown that the YASA has significant cost benefits compared with other axial flux topologies, and radial flux machines [8].

Owing to the high combined length of the two air-gaps, YASA motors generally exhibit low self-inductance. This can be problematic for fault-tolerant designs, as it results in a high short circuit current, but the low time constant is advantageous for highly dynamic operations, such as torque vectoring [9], [10].

Soft magnetic composite (SMC) has a number of advantages which have been shown to make it preferential in the case of axial flux machines [11], [12]. Laminating steel in the radial direction is a difficult procedure and pressing parts from SMC is generally an easier, and therefore cheaper, operation. SMC exhibits lower iron losses, leading to greater efficiencies at higher operating frequencies [13].

This article builds on previous work reported in [14] with additional thermal simulation and experimental results.

\section{DESIGN}

\section{A. Requirements}

The motor has been designed to fit into a space with a diameter of $380 \mathrm{~mm}$ and a length of $125 \mathrm{~mm}$, giving an aspect ratio of approximately 3 . It is required to produce $70 \mathrm{Nm}$ continuously at $350 \mathrm{rpm}$, with a maximum speed of $1400 \mathrm{rpm}$.

\section{B. Topology}

There are a number of factors to consider when choosing the slot/pole combination. The number of slots (and hence coils) and poles (magnets) should be similar to allow good flux linkage through the coil, but not identical. The coil number should be even to prevent vibrations caused by unbalanced magnetic forces. Finally, a slot/pole combination with a higher lowest common divisor (LCD) will result in better torque quality and lower harmonics than one with a lower LCD [12]. Machines with pole numbers which are a multiple of 5 or 7 fulfil this last criterion and so are often used. 
A topology of 24 stator coils and 28 rotor poles was chosen, as it satisfies all of the above requirements, and results in a design with practical dimensions given the available space. With 14 pole pairs, the fundamental electrical frequency at maximum speed is $327 \mathrm{~Hz}$.

\section{Materials}

Owing to the need for high efficiency, and the relatively high electrical frequency, solid steel cannot be considered for the stator teeth as it would result in unacceptable eddy current losses. A conventional steel lamination is difficult to manufacture for this purpose since it would require the laminations to be perpendicular to the axis of the machine. A pressed SMC component allows a flexible tooth design to accommodate the coils, whilst maintaining low loss. Höganäs $\mathrm{AB}$, Sweden, produce a range of SMC materials with varying properties. High strength, high resistivity Somaloy 700HR-3P has been used for simulation, but a machinable prototyping material is used for the prototype motor described in this paper.

An SMC ring is also used to form the rotor corebacks. Sintered N35SH grade magnets are bonded to the rotor corebacks, which are in turn attached to stainless steel rotor discs providing mechanical support of the rotor and transmission of the torque to the shaft. The magnets are manufactured in four segments to reduce losses.

Proximity to the windings and large leakage flux between adjacent teeth in the YASA machine [8] can induce high eddy currents in the support material if it is electrically conductive, causing losses. To ensure high efficiency, a glass fibre reinforced plastic (GFRP) material, Tufnol 10G/42, was chosen for this part. This presents challenges for cooling which are discussed below [15].

The structure of the machine is shown in Fig. 1.

The axial field produces high axial forces which are magnified by the large diameter. To prevent these forces from causing the air-gap length to vary in operation, the stator is supported at the outer diameter by thick aluminium outer housing plates and the rotor magnets and coreback by stainless steel plates. The shaft is mounted to the stator via a bearing arrangement which uses tapered roller bearings within separate seats to allow correct pre-loading. This mechanical arrangement provides a suitably stiff structure to maintain the correct air-gap under the axial load, but could be further optimised to reduce mass, for example, by supporting the stator from the inner diameter using a suitable material and design. However, this is beyond the scope of this paper. Further discussion of measures to ensure robust mechanical design of YASA machines can be found in [16].

\section{Cooling}

The need for relatively high current density [17] in the coils to achieve the necessary power density creates a significant source of heat power which, along with iron losses from the stator pole pieces, needs to be dissipated to the environment to maintain the temperature within acceptable limits. Liquid cooling is common for electric motors in automotive traction applications, but there are practical challenges with

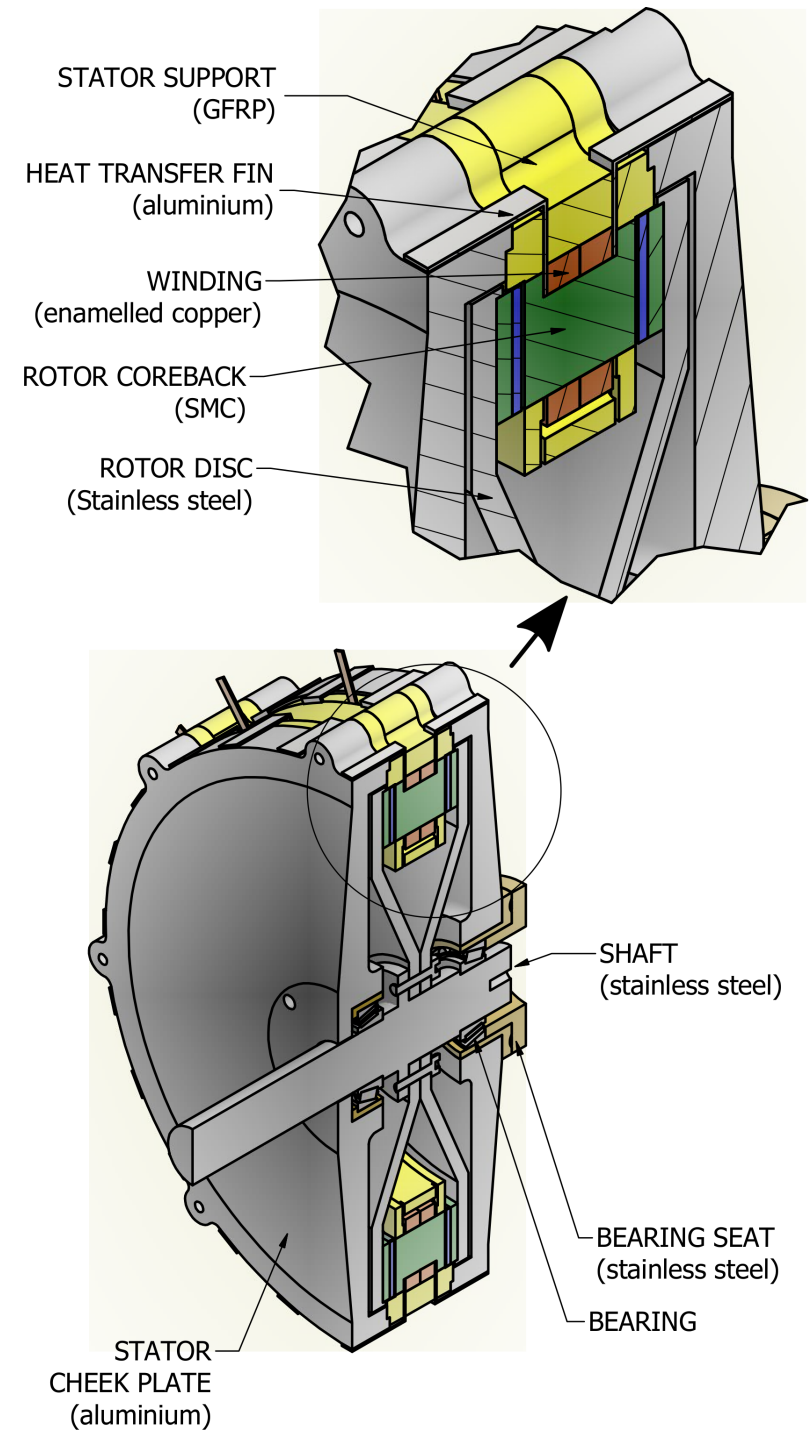

Fig. 1: Structure of prototype motor

this method in the in-wheel setting. Air cooling by forced convection, where a fan is used to increase airflow over the motor and therefore increase the rate of heat dissipation, presents another option. This has been shown to increase the continuous power rating of a YASA motor by $43 \%$, according to the manufacturer's claims [18]. However, research into this cooling method [19] and the design of the fan [20] has not considered external airflows which might be encountered in a in-wheel situation, likely because this would be very difficult to generalise. Furthermore, the additional weight and axial space required by a cooling fan would be particularly disadvantageous for an in-wheel motor. It should be noted that rotor cooling is the main aim of forced convection, whereas the method proposed in this work deals mainly with heat from the stator. While the two heat sources are not independent, these two methods could be applied together, but forced convection will not be considered further in this work.

Typically, cooling by natural convection limits the current density in the windings to a maximum of $5 \mathrm{Amm}^{-2}$ [21]. The GFRP stator support, with its poor thermal conductivity, 
does not provide a sufficient thermal path for the heat, and so an additional path must be provided. Previously, aluminium fins have been used to reduce thermal resistance between the source of heat (principally the winding) and a liquid-cooled surface [22].

In this work, aluminium heat transfer fins have been added to each stator tooth, sited between the coil and tooth, and extending out to the outer aluminium housing where they are bolted at a joint with a large surface area, and using thermal compound to provide a good thermal contact.

The use of heat transfer fins has been demonstrated in [23] with some significant differences. In [23], the heat transfer fins are an integral part of a laminated stator housing, and are placed between the coils rather than on the axial faces. Because of this and the use of a laminated stator core, there is no direct contact with the heat transfer fins as with the SMC cores in this work.

The design of the fins and their interface with the coil is a compromise between good thermal conductivity along the heat path and good electrical resistivity. It should be recognised that eddy currents may be induced in the fins by the magnetic field produced by the winding. Accordingly, the fins are slotted in the direction of the heat flow to create shorter paths for the eddy currents whilst having minimal effect on the heat flow in the required direction. Additionally, the fins are lacquered to improve isolation across the slots. Kapton tape is used to provide electrical insulation between the fin and coil; this introduces some parasitic thermal resistance, but minimises the risk of short circuits.

A schematic diagram of a single fin, tooth, and coil assembly is shown in Fig. 2.
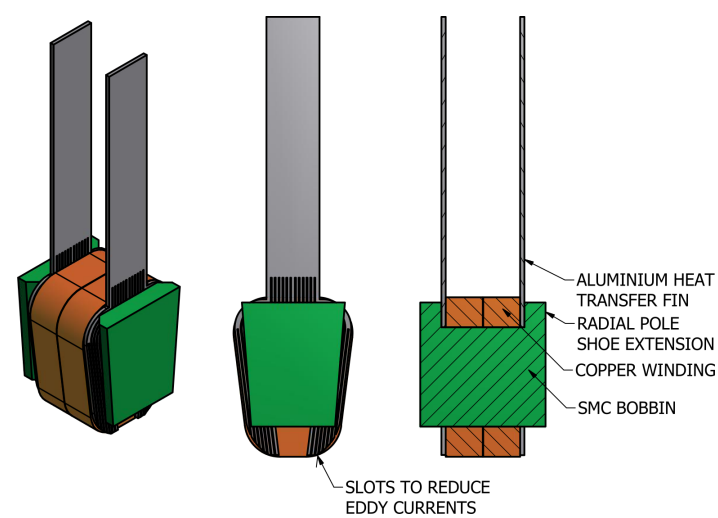

Fig. 2: Tooth, coil and cooling fin assembly

\section{ANALYSIS}

\section{A. Electromagnetic Analysis}

An iterative process was used to produce a YASA motor design meeting the requirements set out previously. The JMAG finite element analysis (FEA) software was used to carry out a transient analysis of the design and evaluate the electromagnetic characteristics and torque production.
The simulation calculates the inductance in the q-axis as $774.3 \mu \mathrm{H}$ and the back EMF at $350 \mathrm{rpm}$ to be $29.1 \mathrm{~V}_{\text {rms }}$. The steady-state short circuit current can be calculated as

$$
I_{\mathrm{SC}}=\frac{E}{\omega L_{q}}
$$

giving a value of $73.2 \mathrm{~A}$. This is $14 \%$ higher than the rated overload current of $64.2 \mathrm{~A}$.

The electromagnetic FEA allows the impact of eddy-current losses in the heat transfer fins to be assessed. The results show that $15 \mathrm{~W}$ of loss occurs in the heat transfer fins at $1400 \mathrm{rpm}$ with $6.4 \mathrm{Amm}^{-2}$ in the windings. This represents $3 \%$ of the total loss at this operating point, but the overall motor efficiency is only reduced from 92.31 to $92.13 \%$

\section{B. Thermal Analysis}

Thermal performance affects both long-term (continuous operating power) and short-term (overload) capabilities of the machine. The maximum continuous operating power can be inferred from the power loss which causes a chosen maximum steady-state temperature rise-to the point at which thermal equilibrium is reached-when applied continuously. The overload rating is determined by the transient thermal performance: how quickly the temperature rises for a given power loss. Both these measures are heavily dependent on the physical properties of the materials used in the construction of the machine, the nature of the contacts between them and the heat exchange mechanisms with the surrounding air.

Two 3-D finite element models - with and without a heat transfer fin-were constructed to assess the effectiveness of the fins. The finned model with its finite element mesh is shown in Fig. 3. The JMAG software was also used for the thermal analysis. The symmetry of the stator has been exploited to reduce the complexity of the model: one stator tooth segment (one 24th of the complete stator) has been divided in two both axially and circumferentially, with zero heat flux conditions imposed on each of these boundaries to represent this symmetry.

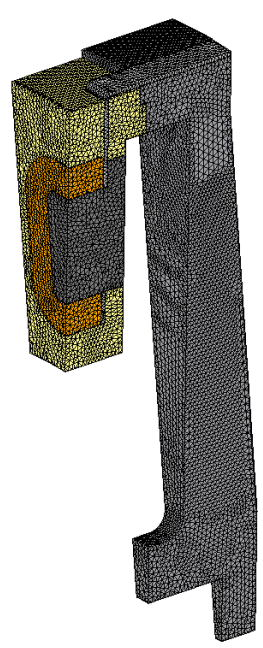

Fig. 3: Finned thermal FEA model with mesh 
The loss is approximated by calculating the resistive loss in the coil at nominal rated current density $\left(5 \mathrm{Amm}^{-2}\right)$ based on its dimensions and the resistivity of copper at $150^{\circ} \mathrm{C}$. Since the loss cannot change with temperature in the chosen simulation environment, the resistivity at $150^{\circ} \mathrm{C}$ is used, which is approximately 1.5 times higher than at $20^{\circ} \mathrm{C}$, and is a conservative assumption. All the loss is modelled as originating in the coil; again, this is a worst-case assumption since the coil has the most thermally resistive heat path to the ambient air.

Some parameters of the model are known from material data, and some are set using assumptions from following common approaches to representing the real situation [24].

The thermal conductivity and specific heat capacity which characterise the bulk thermal properties of the aluminium housing and fin, the GFRP structure, and the SMC pole are generally available. The coil is more complex since it consists of copper, insulation, and air, and is anisotropic. An approximation of the coil is made by replacing it with a homogeneous material with thermal properties in proportion to the relative volumes of copper and air, and discounting the insulation. The material constants used are summarised in Table I.

The contact resistance between the different components of the stator assembly affect the transfer of heat from the coils to the outer housing surface but are dependent on many variables, such as the pressure applied to the interface, and the roughness and hardness of the surfaces [25]. In this model, they are represented by thermal resistances equivalent to a layer of air of a given thickness. The air thickness between the inside and axial end of the coil, and the tooth (and where appropriate, fin) is assumed to be $0.05 \mathrm{~mm}$. Between the outside of the coil and the surrounding support material, a $1 \mathrm{~mm}$ air gap is assumed. The other contacts, between the tooth, support material, fin, and housing, are represented by $0.1 \mathrm{~mm}$ air gaps.

The rate of heat dissipation to the ambient air affects the steady-state temperature for a given power input. Two mechanisms dominate the process: convection and radiation. Both are difficult to precisely determine, being affected by such volatile factors as airflow regimes, surface finishes, and the orientation of the machine. However, approximations are available based on empirical data.

The following relationship for natural (unforced) convective cooling of a machine in an unfinned cylindrical housing of

TABLE I: Summary of materials used in the thermal model and their properties

\begin{tabular}{ccc}
\hline Material & $\begin{array}{c}\text { Thermal } \\
\text { Conductivity } \\
\left(\mathbf{W m}^{-1} \mathbf{K}^{-1}\right)\end{array}$ & $\begin{array}{c}\text { Specific Heat } \\
\text { Capacity } \\
\left(\mathbf{J k g}^{-1} \mathbf{K}^{-1}\right)\end{array}$ \\
\hline \hline Winding simple composite & 294.4 & 550.2 \\
SMC (Somaloy Prototype) & 23 & 450 \\
Aluminium & 230 & 900 \\
GFRP (Tufnol 10G/42) & 0.45 & 1007 \\
\hline aProportional composite of 73.4\% copper (401 & $\mathrm{Wm}^{-1} \mathrm{~K}^{-1}$, \\
$\left.380 \mathrm{Jkg}^{-1} \mathrm{~K}^{-1}\right)$ and the remainder air $(0.0262$ & $\mathrm{Wm}^{-1} \mathrm{~K}^{-1}$, \\
$1020 \mathrm{Jkg}^{-1} \mathrm{~K}^{-1}$ ) & & \\
\end{tabular}

diameter $D$ is used:

$$
h_{C}=k_{C 1} \cdot\left(\frac{\Delta T}{D}\right)^{0.25}
$$

where $\Delta T$ is the temperature difference between the housing and ambient and $k_{C 1}$ is found to be 1.30 from comparison with results from computational fluid dynamics studies [26].

The importance of radiation in motors without forced cooling is noted in [26] and [27]. The heat flux due to radiation is dependent on the temperature difference and the emissivity coefficient of the surface. Whilst the latter is highly dependent on surface finish, an approximation of 0.2 is used for the aluminium housing and 0.75 for the GFRP support material [28]. A temperature-dependent heat transfer coefficient combining the effects of radiation and convection is used in the simulation.

Heat is also transferred from the internal surfaces into the air inside the motor, which is affected by the movement of the rotor and airflow inside the machine, and is hence too complex for in-depth analysis here. The prototype motor is totally enclosed, and so an approximation based on work on totally-enclosed fan-cooled machines in [29], using the worstcase assumption of a stationary rotor. This allows the Nusselt number, representing the affect of the airflow regime, to be set at 2. Hence a heat transfer coefficient based on the air-gap length and conductivity of air can be calculated. The internal air temperature is assumed to be constant at $80^{\circ} \mathrm{C}$.

The steady-state thermal simulation determines the temperature of each element in thermal equilibrium. The maximum temperature is found to be at the centre of the coil crosssection, in the middle of the inner end region, and this point is used as an indicator of the thermal performance. Under the conditions described above, the steady-state maximum temperature is calculated to be $157.8^{\circ} \mathrm{C}$ for the model without a heat transfer fin, as seen in the shaded temperature plot in Figure $4 b$.

The model with the heat transfer fin was simulated with varying heat input until the same steady-state maximum temperature was achieved. This was found to correspond to a loss equivalent to a current density of $6.9 \mathrm{Amm}^{-2}$, representing a $39.7 \%$ increase in allowable current density through the use of the heat transfer fin, and the temperature distribution for this case is shown in $4 a$.

\section{EXPERIMENTAL VALIDATION}

\section{A. Motorette Thermal Testing}

To validate the thermal performance of the stator prior to manufacture of the full motor, two 'motorettes' were produced, each representing a single stator pole section consisting of a single coil wound on an SMC pole piece enclosed in a GFRP segment. One motorette contains heat transfer fins and one does not, but the coils in each are identical. During testing the motorettes are surrounded by fibreglass insulation on four sides. This recreates the circumferential boundary condition in the full motor; no heat flows between neighbouring segments as they produce equal average loss. The dissipation to the internal air is difficult to replicate accurately and consistently 
in this scenario, and so insulating the axial surfaces ensures the reliability of the comparison.

Thermocouples were embedded in the motorettes to measure the temperature, and the loss is generated by injecting a DC current into the coil. This concentrates the loss in the coil, ignoring the generation of heat in the core due to iron loss, and represents a worst-case situation. The outer ends of the heat transfer fins in the finned motorette are bolted to an aluminium block, which acts as a heatsink representing the motor housing, using thermal compound. The finned motorette is shown in Fig. 5 and with the insulation and heatsink block in Fig. 6.

To determine the effect of the fins on the continuous rating of the machine, the temperature in the hottest part of the coil (in the same place as the FE model) in the motorette without fins is measured under continuous rated conditions (current density of $5 \mathrm{Amm}^{-2}$ ) until thermal equilibrium is reached. The current density which causes the same steady-state temperature rise in the motorette with fins is determined by experiment. This was found to be $7.1 \mathrm{Amm}^{-2}$, an increase in allowable current density of $42 \%$. The measured temperature data for these tests is shown in Fig. 7.

The effect of the heat transfer fins on short-duration overload conditions was assessed by applying the same current

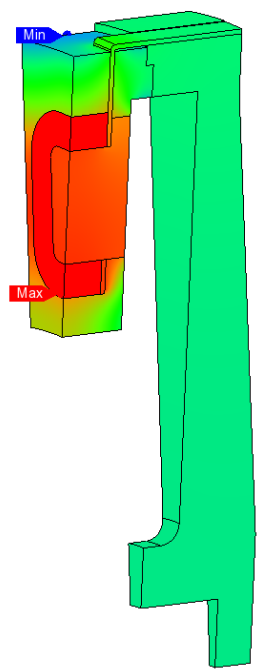

(a) Steady-state temperature plot

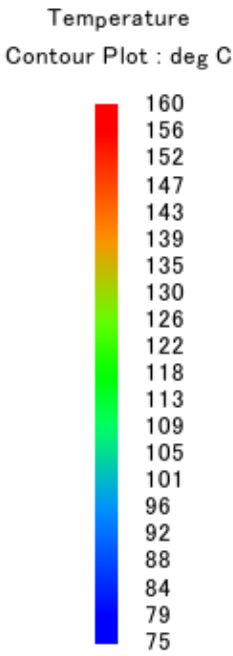

(b) Steady-state temperature plot (no fin)
Fig. 4: Results of FEA with and without heat transfer fin

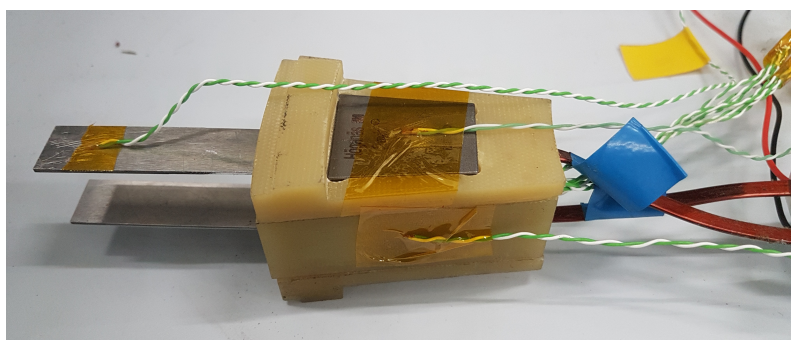

Fig. 5: Motorette assembly for experimental evaluation of heat transfer fins density to each motorette and measuring the time taken for the hottest part of the coil to rise by $150^{\circ} \mathrm{C}$. The current density was set at $10 \mathrm{Amm}^{-2}$, twice the nominal rating. The rise time was found to be $808 \mathrm{~s}$ with fins, but $603 \mathrm{~s}$ without; the fins increase the allowable overload duration by $34 \%$. The results of the overload rating test are shown in Fig. 8 .

The absolute temperature rises seen in the motorettes vary from those found by simulation. This can be attributed to

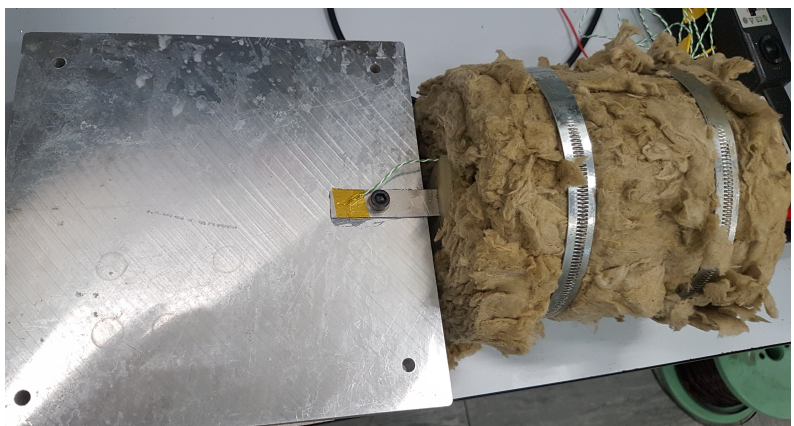

Fig. 6: Finned motorette assembly with insulation and heatsink

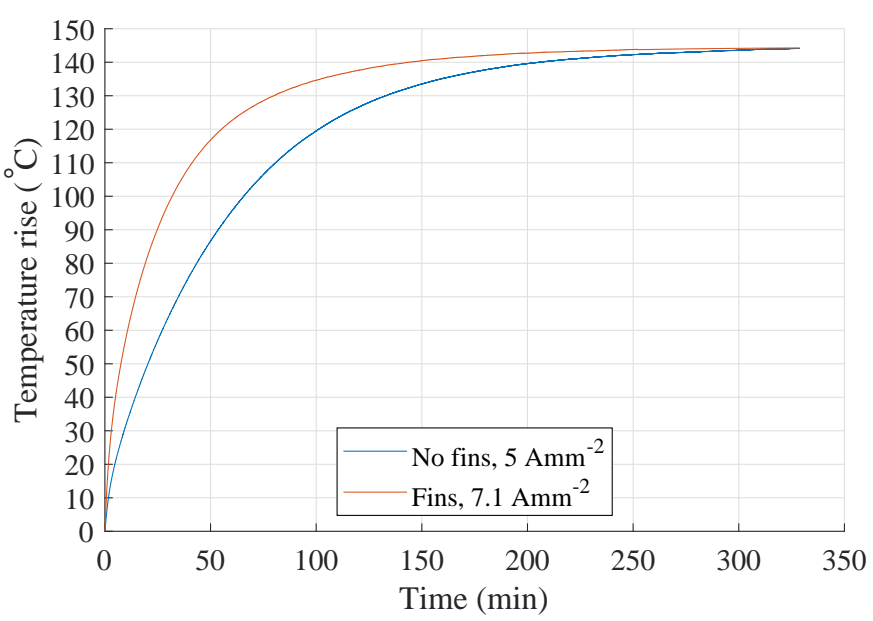

Fig. 7: Measured temperatures in the coils of the two motorettes in the continuous rating test

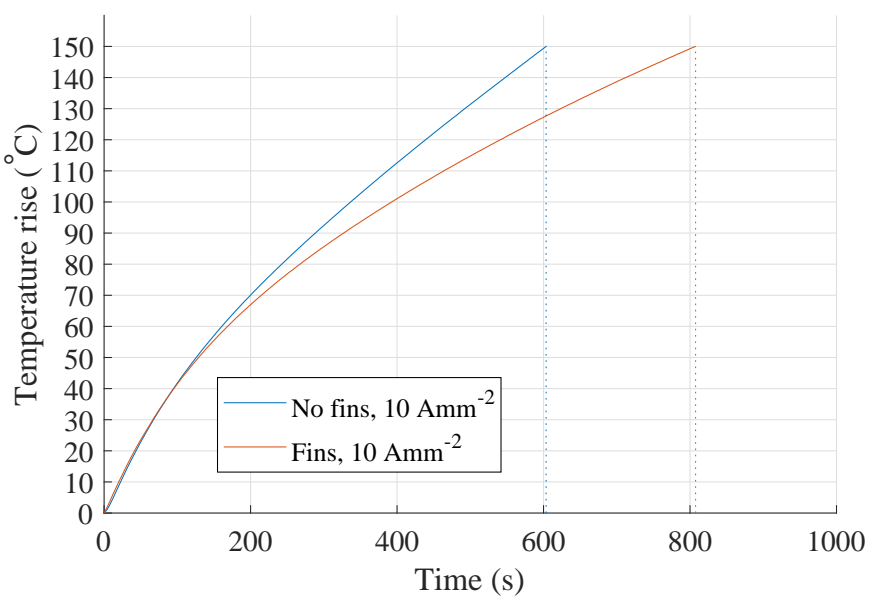

Fig. 8: Measured temperatures in the coils of the two motorettes in the overload rating test 
two differences between the simulation and practical experiments: the FEA fully models the motor housing, whereas an aluminium block is used as a heatsink for the heat transfer fins in the motorette; also, the internal heat dissipation is modelled in the simulation but suppressed with insulation in the motorettes. However, the relative losses required to cause the same temperature rise show good agreement between the simulation and experimental work.

\section{B. Motor Electromagnetic Performance}

The back EMF measured at the terminals of the manufactured prototype motor was compared with the predicted results from the FEA at $350 \mathrm{rpm}$, as shown in Fig. 9. The measured results closely match the simulated results, except for phase L2, which exhibits a back EMF lower by approximately $12 \%$. This is likely to be due to an inter-turn short in one of the coils, and is reflected in DC resistance measurements. This must be accounted for in interpreting other results from the prototype.

The cogging torque and static torque over an electrical cycle at various currents is measured and compared with the FEA results. The amplitude of the measured fundamental electromagnetic torque is a good match to the simulated values, as seen in the static torque characteristics in Fig. 10, but the cogging torque is significantly higher than predicted as can be seen in both Fig. 10 and the cogging torque characteristics in Fig. 11. The cogging torque was predicted to be $3.4 \mathrm{Nm}$ peak-peak, but measured as $7.4 \mathrm{Nm}$ peakpeak, a difference of $117 \%$. This is thought to be due to manufacturing tolerances causing inaccurate placement of the stator segments, but the accuracy of the FEA cogging torque prediction is also uncertain. The average torque of $1.06 \mathrm{Nm}$, arising from friction, has been subtracted from the measured data to isolate the cogging torque. The simulation does not account for friction and so the DC component is already zero. Whilst the angular resolution of the measured torque is not sufficient to accurately recreate the shape of the cogging torque waveform, enough points are captured to give suitable confidence in the peak values of the torque from which the overall cogging torque figure is calculated.

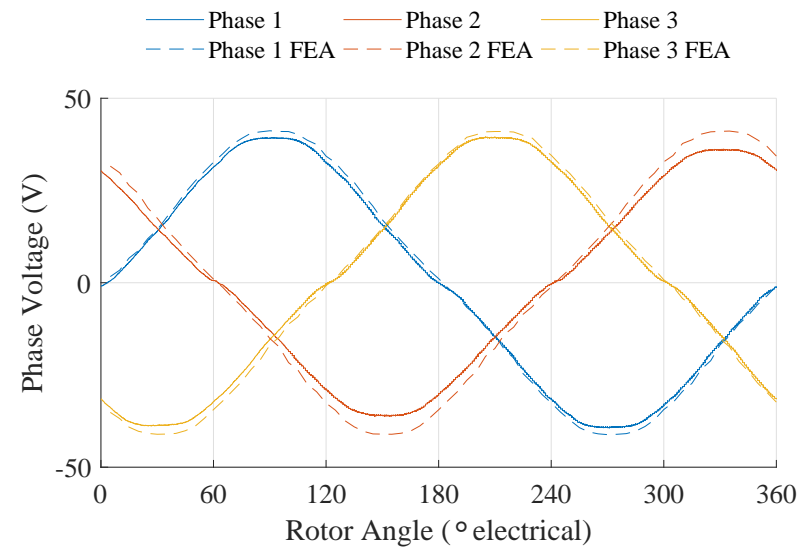

Fig. 9: Comparison of measured and simulated back EMF at $350 \mathrm{rpm}$

\section{Motor Thermal Performance}

The continuous rated current of the machine is considered here to be that which causes a steady-state temperature rise of $125^{\circ} \mathrm{C}$ at rated speed, $350 \mathrm{rpm}$ The current rating is expected to correspond approximately to a current density of $5 \mathrm{Amm}^{-2}$, or $31.2 \mathrm{~A}_{\text {rms }}$. Tests were performed at a continuous current of 31.2 and $36.4 \mathrm{~A}$. Curves were fitted to the data using a least squares nonlinear regression to fit a function of the form $T(t)=A \cdot e^{(-t / B)}+C \cdot e^{(-t / D)}+E$ to the measured data. This models the system as a simple thermal network with two elements: one with a short time constant, corresponding approximately to the coils, and one with a longer time constant, corresponding to the tooth, casing, etc. Using these characteristics, an estimate of 34 A was made for the current to produce a temperature rise of $125^{\circ} \mathrm{C}$. A test was performed at this current and the temperature rise was measured as $125^{\circ} \mathrm{C}$. The results of the three thermal tests at $350 \mathrm{rpm}$ are shown in Fig. 12.

While there is a discrepancy between the simulation and experimental results in the absolute values of current density which cause a given temperature rise, the relative change agrees well. The difference in absolute values likely arises largely due to the use of conservative assumptions for certain

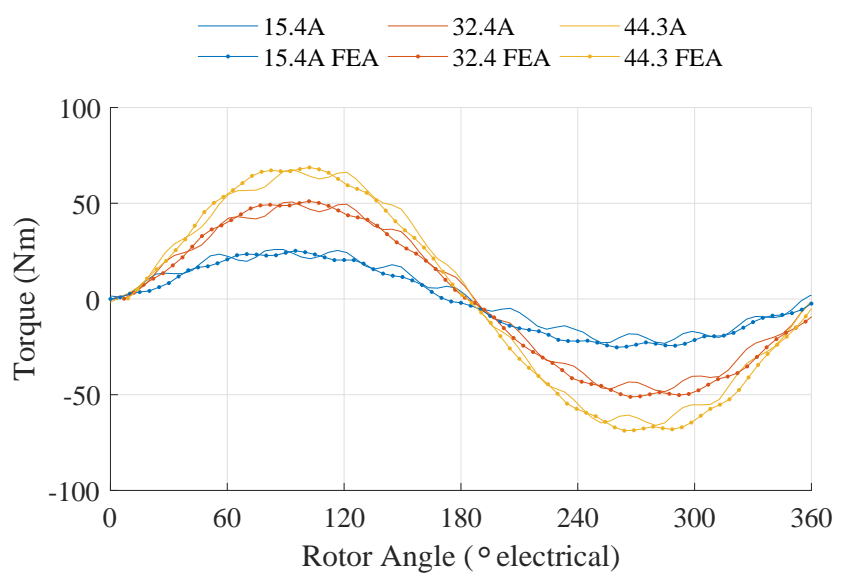

Fig. 10: Comparison of measured and simulated static torque

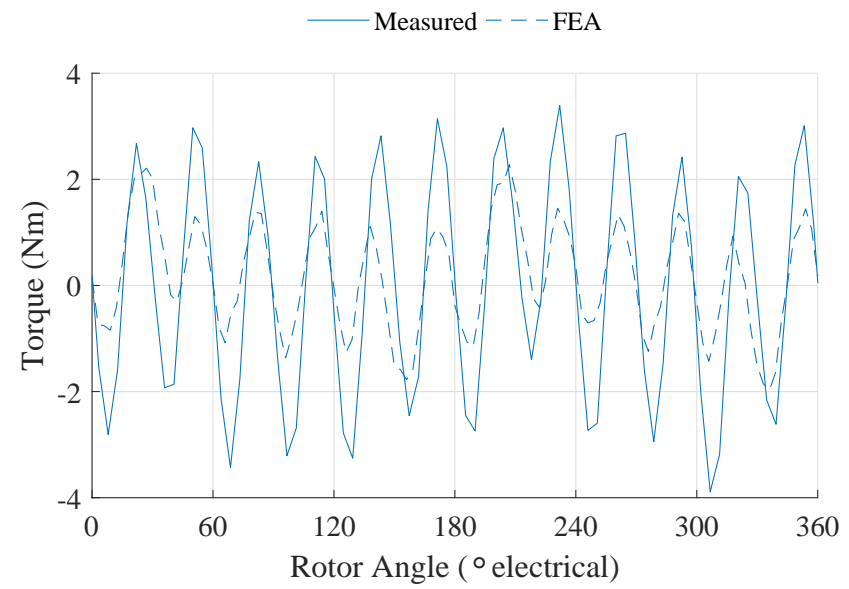

Fig. 11: Comparison of measured and simulated cogging torque 
parameter values in the simulation.

Measured efficiency over the range 0-65 Nm and 0-500 rpm is shown in the efficiency map in Fig. 13.

\section{COnClusions And Future Work}

Cooling is an important aspect of achieving the high power densities required in automotive applications. Air cooling is considerably less effective than liquid cooling but has significant advantages for overall system cost and simplicity if it can be shown to be acceptable.

This paper has presented both analytical and experimental investigations into the air-cooling of a YASA motor for inwheel traction. The results demonstrate that it is possible to achieve the required performance with air-cooling by providing an additional low-resistance heat path to the ambient air. Aluminium heat transfer fins have been designed for this purpose. Results from finite element analysis and experimentation with a physical model have shown that improvements of approximately $40 \%$ in terms of achievable continuous current density are possible. Furthermore, the direct coupling of the heat transfer fins to the coil improves the short duration overload capability of the machine.

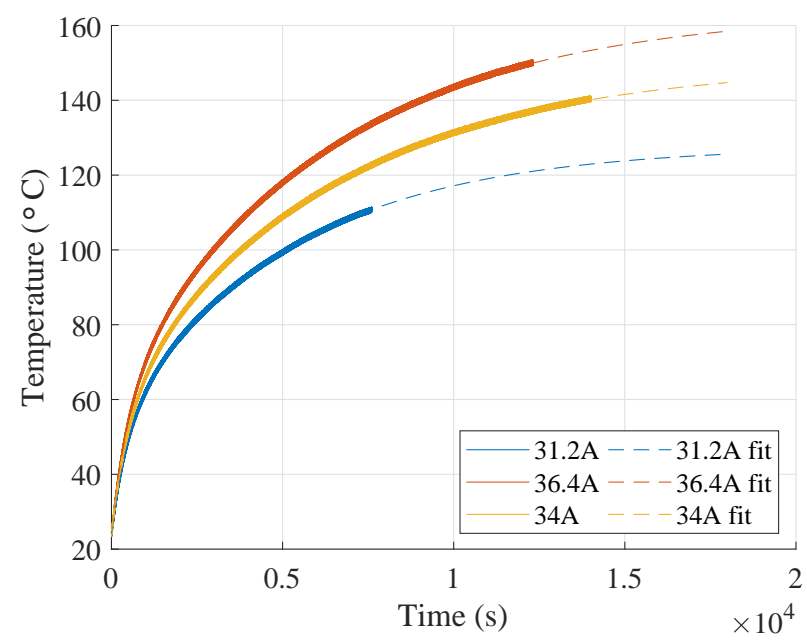

Fig. 12: Thermal test results at $350 \mathrm{rpm}$

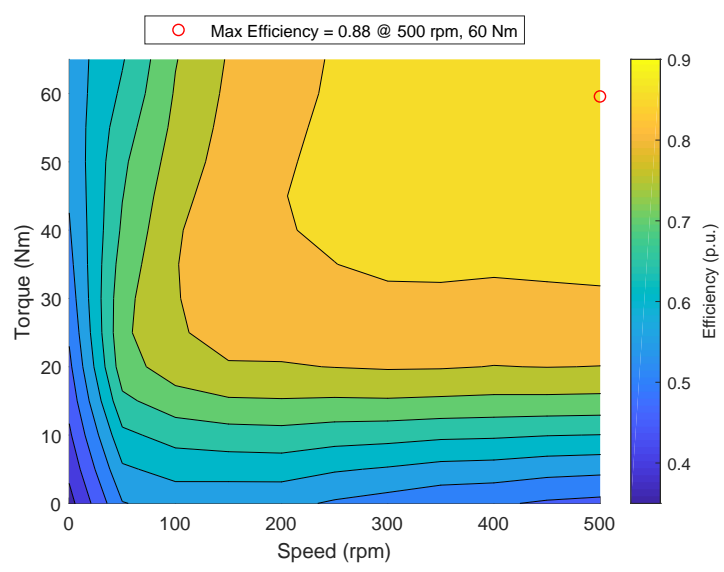

Fig. 13: Map of measured efficiency
Further work could more thoroughly validate the parameters of the finite element model based on experimental measurements, which would enable optimisation of the design of the heat transfer fins. Validation could also enable simplification in the form of a lumped-parameter model, enabling the effect of design changes on thermal performance to be evaluated more quickly [24]. A more accurate model of the complex structure of the coil could be produced by tests on a bulk sample of the winding using techniques discussed in [30] and [31]. The model currently only considers loss generated in the winding; analysis of how losses in the core influence the thermal performance could be used to optimise the electromagnetic design of the motor. Further consideration of practical issues such as the orientation of the machine and airflow regimes around it would help to inform the integration of the machine in the intended application.

\section{REFERENCES}

[1] P. Gottipati, O. Dobzhanskyi, and E. A. Mendrela, "In-wheel brushless DC motor for a wheel chair drive," in 2010 Joint International Conference on Power Electronics, Drives and Energy Systems \& 2010 Power India, Dec 2010, pp. 1-4.

[2] J. Lee, J. Kim, and B. Woo, "Optimal design of in-wheel motor for an E-bike," in 2016 IEEE Transportation Electrification Conference and Expo, Asia-Pacific (ITEC Asia-Pacific), June 2016, pp. 441-443.

[3] C. Feng, X. Jing, G. Bin, C. Shukang, and Z. Jiange, "Double-stator permanent magnet synchronous in-wheel motor for hybrid electric drive system," IEEE Transactions on Magnetics, vol. 45, no. 1, pp. 278-281, Jan 2009.

[4] S. Ko, C. Song, J. Park, J. Ko, I. Yang, and H. Kim, "Comparison of braking performance by electro-hydraulic ABS and motor torque control for in-wheel electric vehicle," in 2013 World Electric Vehicle Symposium and Exhibition (EVS27), Nov 2013, pp. 1-6.

[5] C. J. Ifedi, B. C. Mecrow, J. D. Widmer, G. J. Atkinson, S. T. M. Brockway, and D. Kostic-Perovic, "A high torque density, direct drive inwheel motor for electric vehicles," in 6th IET International Conference on Power Electronics, Machines and Drives (PEMD 2012), March 2012, pp. 1-6.

[6] D. J. Patterson, J. L. Colton, B. Mularcik, B. J. Kennedy, S. Camilleri, and R. Rohoza, "A comparison of radial and axial flux structures in electrical machines," in 2009 IEEE International Electric Machines and Drives Conference, May 2009, pp. 1029-1035.

[7] T. J. Woolmer and M. D. McCulloch, "Analysis of the yokeless and segmented armature machine," in 2007 IEEE International Electric Machines Drives Conference, vol. 1, May 2007, pp. 704-708.

[8] N. J. Stannard, J. G. Washington, and G. J. Atkinson, "A comparison of axial field topologies employing SMC for traction applications," in 2016 19th International Conference on Electrical Machines and Systems (ICEMS), Nov 2016, pp. 1-6.

[9] S. De, M. Rajne, S. Poosapati, C. Patel, and K. Gopakumar, "Lowinductance axial flux BLDC motor drive for more electric aircraft," IET Power Electronics, vol. 5, no. 1, pp. 124-133, 2012.

[10] N. Bianchi, M. D. Pre, and S. Bolognani, "Design of a fault-tolerant IPM motor for electric power steering," IEEE Transactions on Vehicular Technology, vol. 55, no. 4, pp. 1102-1111, 2006.

[11] G. Cvetkovski, L. Petkovska, M. Cundev, and S. Gair, "Improved design of a novel PM disk motor by using soft magnetic composite material," IEEE Transactions on Magnetics, vol. 38, no. 5, pp. 3165-3167, Sept 2002.

[12] K. Kim, "A novel method for minimization of cogging torque and torque ripple for interior permanent magnet synchronous motor," IEEE Transactions on Magnetics, vol. 50, no. 2, pp. 793-796, Feb 2014.

[13] D. Gumbleton-Wood, G. Atkinson, J. Washington, and L. Sjöberg, "The influence of production methods on the magnetic performance of electrical steels and soft magnetic composites," in 2017 IEEE International Electric Machines and Drives Conference (IEMDC), May 2017, pp. 1-7.

[14] D. Winterborne, N. Stannard, L. Sjöberg, and G. Atkinson, "An aircooled YASA motor for in-wheel electric vehicle applications," in 2019 IEEE International Electric Machines Drives Conference (IEMDC), 2019, pp. 976-981. 
[15] S. Kahourzade, A. Mahmoudi, H. W. Ping, and M. N. Uddin, "A comprehensive review of axial-flux permanent-magnet machines," Canadian Journal of Electrical and Computer Engineering, vol. 37, no. 1, pp. 1933, 2014.

[16] B. Zhang, Y. Wang, M. Doppelbauer, and M. Gregor, "Mechanical construction and analysis of an axial flux segmented armature torus machine," in 2014 International Conference on Electrical Machines (ICEM), 2014, pp. 1293-1299.

[17] T. A. Lipo, Introduction to AC Machine Design, 1st ed. Wiley, 2017, p. 285.

[18] A. S. Fawzal, R. M. Cirstea, K. N. Gyftakis, T. J. Woolmer, M. Dickison, and M. Blundell, "The fan design impact on the rotor cooling of axial flux permanent magnet machines," in 2016 XXII International Conference on Electrical Machines (ICEM), 2016, pp. 2725-2731.

[19] B. Streibl and H. Neudorfer, "Investigating the air flow rate of selfventilated traction motors by means of computational fluid dynamics," in SPEEDAM 2010, 2010, pp. 736-739.

[20] A. S. Fawzal, R. M. Cirstea, K. N. Gyftakis, T. J. Woolmer, M. Dickison, and M. Blundell, "Fan performance analysis for rotor cooling of axial flux permanent magnet machines," IEEE Transactions on Industry Applications, vol. 53, no. 4, pp. 3295-3304, 2017.

[21] Y. Yang, B. Bilgin, M. Kasprzak, S. Nalakath, H. Sadek, M. Preindl, J. Cotton, N. Schofield, and A. Emadi, "Thermal management of electric machines," IET Electrical Systems in Transportation, vol. 7, no. 2, pp. 104-116, 2017.

[22] B. Bedkowski, P. Dukalski, T. Jarek, and T. Wolnik, "The efficiency analysis of various structural solutions of the wheel motor cooling systems," in 2018 XIII International Conference on Electrical Machines (ICEM), 2018, pp. 995-1000
[23] H. Vansompel, A. Hemeida, and P. Sergeant, "Stator heat extraction system for axial flux yokeless and segmented armature machines," in 2017 IEEE International Electric Machines and Drives Conference (IEMDC), 2017, pp. 1-7.

[24] A. Boglietti, A. Cavagnino, D. Staton, M. Shanel, M. Mueller, and C. Mejuto, "Evolution and modern approaches for thermal analysis of electrical machines," IEEE Transactions on Industrial Electronics, vol. 56, no. 3, pp. 871-882, 2009.

[25] N. Simpson, T. Duggan, P. H. Mellor, and J. D. Booker, "Measurement of the thermal characteristics of a stator-housing interface," in 2017 IEEE 11th International Symposium on Diagnostics for Electrical Machines, Power Electronics and Drives (SDEMPED), Aug 2017, pp. 557-564.

[26] D. A. Staton and E. So, "Determination of optimal thermal parameters for brushless permanent magnet motor design," in Conference Record of 1998 IEEE Industry Applications Conference. Thirty-Third IAS Annual Meeting, vol. 1, Oct 1998, pp. 41-49.

[27] A. Boglietti, A. Cavagnino, M. Parvis, and A. Vallan, "Evaluation of radiation thermal resistances in industrial motors," IEEE Transactions on Industry Applications, vol. 42, no. 3, pp. 688-693, 2006.

[28] M. Zeljković, L. Zorana, B. Strbac, A. Zivkovic, D. Igor, and M. Hadžistević, "The determination of the emissivity of aluminium alloy AW 6082 using infrared thermography," Journal of Production Engineering, vol. 18, no. 1, 2015.

[29] P. H. Mellor, D. Roberts, and D. R. Turner, "Lumped parameter thermal model for electrical machines of TEFC design," IEE Proceedings $B$ Electric Power Applications, vol. 138, no. 5, pp. 205-218, 1991.

[30] P. Romanazzi, M. Bruna, and D. A. Howey, "Thermal homogenization of electrical machine windings applying the multiple-scales method," AMSE Journal of Heat Transfer, vol. 139, no. 1, Aug 2016.

[31] P. Romanazzi, S. Ayat, R. Wrobel, and D. A. Howey, "3D homogenisation of concentrated windings with rectangular conductors," in 2017 IEEE International Electric Machines and Drives Conference (IEMDC), May 2017, pp. 1-8. 